\title{
Shortterm evaluation of non-absorbable microgranular hydroxyapatite infiltration in the guinea pig subepidermal abdominal region
}

\footnotetext{
A.P. Xavier ${ }^{1}$,

S.A. Schellini ${ }^{1}$,

F.F. Aragon ${ }^{2}$,

C.R. Padovani ${ }^{2}$

and E.M. Taga ${ }^{3}$
}

\author{
${ }^{1}$ Departamento de O ftalmologia, O torrinolaringologia e \\ Cirurgia de Cabeça e Pescoço, Faculdade de Medicina de Botucatu, \\ Universidade Estadual Paulista, Botucatu, SP, Brasil \\ ${ }^{2}$ Departamento de Bioestatística, Instituto de Biociências, \\ Universidade Estadual Paulista, Botucatu, SP, Brasil \\ ${ }^{3}$ Departamento de Bioquímica, Faculdade de O dontologia de Bauru, \\ Universidade de São Paulo, Bauru, SP, Brasil
}

\section{Correspondence \\ S.A. Schellini \\ Departamento de O ftalmologia, \\ O torrinolaringologia e Cirurgia \\ de Cabeça e Pescoço \\ Faculdade de Medicina de Botucatu \\ UNESP \\ 18618-000 Botucatu, SP \\ Brasil \\ E-mail: sartioli@fmb.unesp.br}

Research supported by PIBIC-CN Pq Publication supported by FAPESP

Received November 27, 2000 Accepted August 27, 2001

\section{Abstract}

Non-absorbable microgranular hydroxyapatite was infiltrated into the subepidermal abdominal region of guinea pigs in order to assess the possibility of using this material to correct deficiencies in orbital volume. Microgranular hydroxyapatite $(2.0 \mathrm{ml})$ was subepidermally infiltrated into the abdominal region of 20 guinea pigs. The animals were divided into four experimental groups of 5 animals each, which were killed 7 (G1), 15 (G2), 30 (G3) and 60 (G4) days after infiltration. The area and the largest and smallest diameters of the nodules formed by infiltration were evaluated at the site of infiltration and histological examination was performed. The mean granuloma area was similar in all groups. Histopathological examination showed that the material remained isolated from surrounding tissues by a pseudocapsule that became denser throughout the experiment. A host reaction started with young fibroblastic tissue that evolved to dense tissue until cartilaginous tissue was formed in G4, progressively advancing towards the center of the granuloma from G1 to G4. Non-absorbable microgranular hydroxyapatite is an inert material that was well tolerated by the animals studied, with maintenance of the infiltrated volume, and may perhaps be useful to fill anophthalmic cavities.

\section{Key words}

- Infiltration

- Microgranular hydroxyapatite

- Guinea pigs

- Histopathology

\section{Introduction}

The loss of the ocular globe provokes undesirable aesthetic and psychological effects. In order to minimize these effects it is necessary to reestablish the appearance by restoring the orbital volume, which is not always a simple procedure. Volume replacement can be made by the insertion of spheres made of many materials and of different sizes using different surgical techniques.

One of the materials most frequently utilized today for this purpose is hydroxyapatite (HA), which is similar to bone and grows on coral reefs. When it becomes attached to ocular muscles, it acts as a net for fibrovascular proliferation, allowing their synchronic movement (1). There are also spheres of 
synthetic HA and polyethylene.

Regardless of the type of material of which they are made, the spheres should not be very large, since this would facilitate their extrusion (2). The choice of sphere size is difficult and a deficit of orbital volume persists in many individuals with anophthalmic cavities, causing a certain degree of enophthalmos.

In order to improve the adequacy of orbital volume, one attempt was made by infiltrating a substance into the anophthalmic cavity. Thus, the objective of the present study was to demonstrate experimentally the effects of the infiltration of non-absorbable microgranular HA by infiltrating it subepidermally in guinea pigs.

\section{Material and Methods}

Microgranular semi-solid HA was subepidermally infiltrated into the abdominal region of 20 guinea pigs. The animals were supplied by the Central Animal House, Botucatu Campus, UNESP.

The synthetic microgranular HA employed $\left(\mathrm{Ca}_{10}\left(\mathrm{PO}_{4}\right)_{6}(\mathrm{OH})_{2}\right)$ was available in semi-solid form and was developed by one of the authors (3). For infiltration it was necessary to dilute $2.0 \mathrm{ml}$ of the material in $5.0 \mathrm{ml}$ of distilled water.

We analyzed the tecidual reaction after subepidermal infiltration. The animals were divided into four experimental groups of 5 animals each, which received $2.0 \mathrm{ml}$ of HA, using a $30 \times 7$-caliper needle and a $3.0-\mathrm{ml}$ syringe. The animals were killed 7 (G1), 15 (G2), 30 (G3) and 60 (G4) days after infiltration.

After killing the animals, a square $(2.0 \mathrm{x}$ $2.0 \mathrm{~cm}$ ) piece of the abdominal region of guinea pigs where HA was infiltrated (skin and subepidermal tissues) was cut. The pieces were placed on white paper for 3 to $5 \mathrm{~min}$ and then placed in $10 \%$ formaldehyde solution.

After fixation, the pieces were removed from the formaldehyde solution and off the paper, and measurements of the granulomas were performed using a computer image analyzer (Luzex-F-NIRECO). The smallest (d) and the largest diameters (D) were measured in order to calculate the $d / D$ ratio by reconstructing an ellipsoid shape. These parameters were evaluated using one-way analysis of variance (ANOVA) and comparisons between groups were made by the Tukey test (4), with the level of significance set at 0.05 .

The granuloma was cut out of each piece at its largest diameter using a blade over a silicon plate. Fragments were immersed in $70 \%$ alcohol solution for $48 \mathrm{~h}$ and embedded in wax, and sections were cut and stained with hematoxylin-eosin (HE).

Histopathological examination was performed with the experimenter blinded to the animal's groups. Granulomas and surrounding tissues were evaluated, as well as the host reaction.

\section{Results}

\section{Clinical evaluation}

The animals were in good general condition throughout the experiment, presenting good physical activity and eating normally. Two animals (one from G1 and the other from G3) developed an infectious process that resulted in the extrusion of the injected material and were replaced. The remaining animals showed no alterations at the site of infiltration.

\section{Granuloma evaluation}

There was neither a decrease in the granuloma at the inoculation site nor a change in its shape from the time of infiltration to sacrifice. Individual measurements, mean and standard deviation, and results of the statistical comparison of the groups of the granulomas formed after infiltration of non-absorbable microgranular HA infiltration are presented in Table 1. 


\section{Histopathological evaluation}

The events that occurred during the study are summarized in Table 2.

Group 1. The injected material was observed in the subepidermal region above the muscle layer. There were areas of hemorrhage under the dermis and in the muscle layer closest to the HA. Between HA and host tissues there was a pseudocapsule formed by fibroblasts and inflammatory cells, which surrounded the injected material. HA was completely surrounded by a pseudocapsule, and separated from neighboring tissues, forming an elongated nodule. In G1, the nodule was formed by inflammatory cells - neutrophils and monocytes - surrounding the HA, involving about $1 / 10$ to $2 / 10$ of its diameter. There were also young fibroblasts, and newly formed vessels, some of them with red blood cells (Figure 1).

Group 2.HA is seen as small birefringent granules surrounded by the pseudocapsule. Giant cells were observed around the granules. There were also many subepidermal areas of hemorrhage. The pseudocapsule became thicker and denser after fibroblast proliferation. A fibrovascular and inflammatory reaction occupied 2 to $3 / 10$ of the diameter of the nodule. There were darkened areas, most likely the result of calcium crystal deposit, as well as pink homogeneous areas corresponding to collagen. There was a small number of inflammatory cells in the neighboring tissues (Figure 2).

Group 3. Fibrosis became denser (pseudocapsule) around the nodule. HA was surrounded by a fibrovascular response at about the midpoint of the nodule, forming true "septa" with HA blocks. A rich inflammatory reaction consisting of macrophages, sometimes changing to giant cells was present. There were many newly formed vessels around the nodule which was full of red blood cells, and tissue inside the nodule became denser, with areas of collagen. The inflammatory reaction was almost absent in the neighboring tissues (Figure 3).

Group 4. Nodules well separated from neighboring tissues by a dense pseudocapsule were observed. An inflammatory response filled the entire nodule and fibrosis surrounded all the HA. There were also many macrophages, giant cells, calcium deposits, as well as areas of collagen; however, this reaction was absent in the neighboring tissues (Figure 4).

Table 1. Granuloma measurements of groups.

\begin{tabular}{lccccc}
\hline Group & Area & $d$ & $D$ & $d / D$ ratio & Volume \\
\hline G1 & $3.27 \pm 1.43$ & $1.62 \pm 0.52$ & $2.45 \pm 0.54$ & $0.65 \pm 0.14$ & $3.93 \pm 2.24$ \\
G2 & $4.59 \pm 1.36$ & $1.98 \pm 0.32$ & $2.93 \pm 0.46$ & $0.68 \pm 0.11$ & $6.25 \pm 2.97$ \\
G3 & $2.80 \pm 0.93$ & $1.43 \pm 0.22$ & $2.46 \pm 0.53$ & $0.60 \pm 0.14$ & $2.76 \pm 1.33$ \\
G4 & $4.29 \pm 2.05$ & $2.02 \pm 0.50$ & $2.59 \pm 0.61$ & $0.78 \pm 0.07$ & $6.32 \pm 4.63$
\end{tabular}

Data are reported as means $\pm S D$. $D=$ largest diameter; $d=$ smallest diameter. There were no significant differences among groups (ANOVA and Tukey test).

Table 2. Characteristics of histopathological evaluation of the granulomas in the experimental groups.

\begin{tabular}{|c|c|c|c|c|c|}
\hline Group & Animal & PS & $\mathrm{HA}$ & Inflammatory response & OUTI \\
\hline Group 1 & 1 & + & + & $1 / 10$ & - \\
\hline \multirow[t]{4}{*}{ (7 days) } & 2 & + & $+(2$ lobes $)$ & $1 / 10$ & + \\
\hline & 3 & + & + & $1 / 10$ & + \\
\hline & 4 & + & + & $2 / 10$ & + \\
\hline & 5 & + & + & $2 / 10$ & + \\
\hline Group 2 & 6 & ++ & + & $2 / 10$ & - \\
\hline \multirow{4}{*}{ (15 days) } & 7 & ++ & + & $2 / 10$ & - \\
\hline & 8 & ++ & + (in blocks) & $2 / 10$ & + \\
\hline & 9 & ++ & + (2 lobes $)$ & $3 / 10$ & - \\
\hline & 10 & ++ & + & $3 / 10$ & + \\
\hline Group 3 & 11 & ++ & + & $5 / 10$ & - \\
\hline \multirow{4}{*}{ (30 days) } & 12 & +++ & + & $5 / 10$ & - \\
\hline & 13 & - & - & - & - \\
\hline & 14 & +++ & + & Dense & + \\
\hline & 15 & +++ & + & Dense & - \\
\hline Group 4 & 16 & ++++ & + & Dense and generalized & - \\
\hline \multirow[t]{4}{*}{ (60 days) } & 17 & +++ & + & Dense, with fibrosis involving lobes & - \\
\hline & 18 & ++++ & + & Dense and generalized & + \\
\hline & 19 & ++ & - & - & - \\
\hline & 20 & ++++ & + & Dense, with fibrosis until the center & - \\
\hline
\end{tabular}

PS = pseudocapsule; HA = hydroxyapatite; OUTI = inflammatory response in surrounding tissue. 

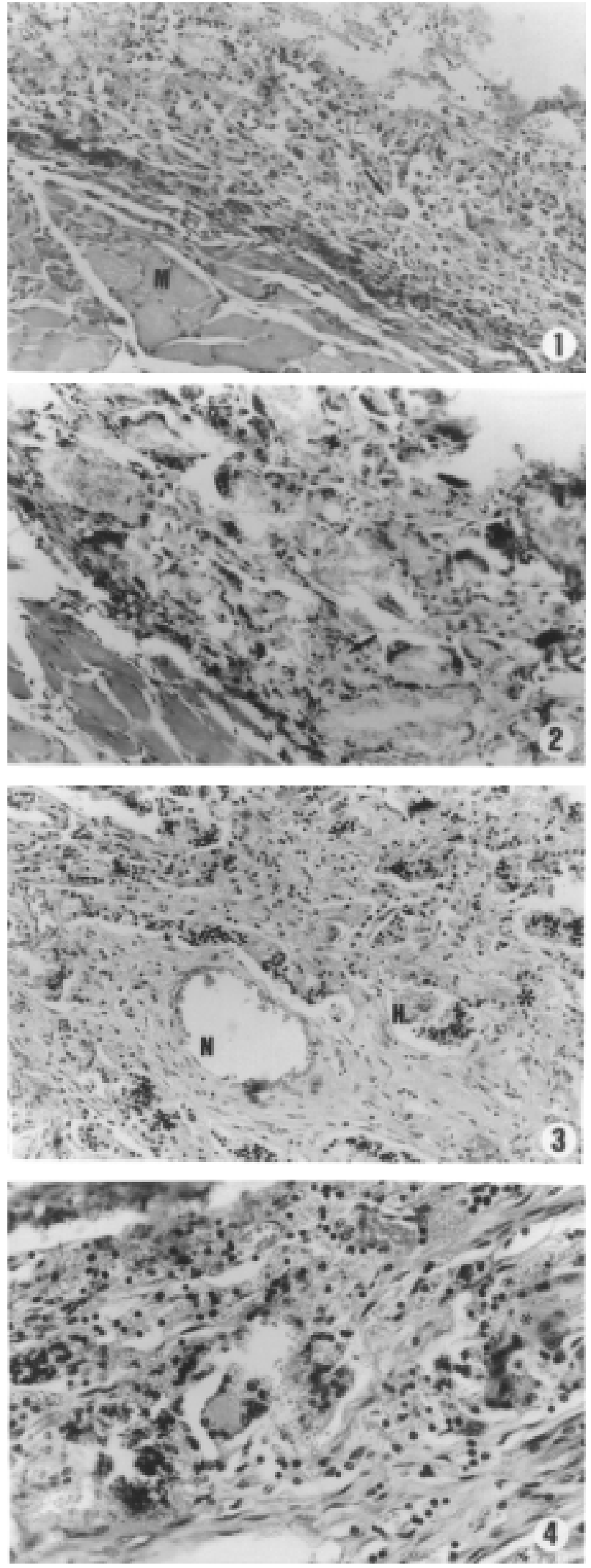

Figure 1. Periphery of the hydroxyapatite nodule. Observe hydroxyapatite with small birefringent granules (arrow) and the inflammatory cells among young fibroblasts. Presence of newly formed vessels and red blood cells. $\mathrm{M}=$ muscle fibers ( $\mathrm{Gl}-\mathrm{HE}, 100 \mathrm{X})$.

Figure 2. Periphery of the hydroxyapatite nodule. Observe the hydroxyapatite granules surrounded by giant cells (arrow). Homogeneous areas corresponding to collagen (G2 - HE, 100X).

Figure 3. The hydroxyapatite granules are surrounded by a fibrovascular and inflammatory reaction that forms true "septa" dividing the hydroxyapatite $(\mathrm{H})$ into "blocks". Collagen $(*)$ was commonly detected in this animal group. $\mathrm{N}=$ newly formed vessel (G3 - HE, 100X).

Figure 4. Birefringent hydroxyapatite granules in a dense fibrovascular response. Giant cells and collagen $(*)$. Newly formed vessels containing red blood cells (G4 - HE, 100X). 


\section{Discussion}

Many studies are being conducted in an attempt to restore orbital volume after the loss of the eye or of its content. Currently, one of the most utilized material for this purpose in the United States is HA in the form of spheres surgically implanted into the orbital cavity. Since it is difficult to fit the volume of the sphere to the cavity, enophthalmos may remain even when spheres are utilized. Several investigators have attempted to use liquid HA, which could be infiltrated into the cavity and would not require surgery for insertion.

HA has been used for the reconstruction of tissues in dentistry and acts by accelerating new bone and tissue formation by releasing calcium and phosphate ions that stimulate the action of fibroblasts and macrophages. HA has high biological compatibility and, depending on the size of its microgranules, can be absorbed by phagocytosis (5).

Histopathologically, we observed the host's response to the HA, which consisted of engulfing and phagocytizing the material used. The giant cell response observed had been previously observed with the use of natural HA (6). A pseudocapsule was formed during the initial phase of the process, which persisted throughout the study period and became denser and thicker, preventing the loss of the substance into surrounding tissues. This fact led to a reduced inflammatory reaction outside the site of inoculation.

The inflammatory reaction close to the infiltrated material occupied an increasingly larger space and its fibroblastic aspect became progressively denser, with the formation of amorphous basophilic tissue similar to cartilaginous tissue. We believe that a longer follow-up of the animals is needed in order to observe the probable new bone formation that occurs with the use of natural HA.

The granuloma format remained unchanged from the HA infiltration until the end of the experiment (60 days). However, this was not homogeneous among the animals. The mean $\mathrm{d} / \mathrm{D}$ ratio varied significantly from the 1.00 target (corresponding to the spherical shape), indicating that the granuloma was of irregular rather than spherical shape.

Nevertheless, the mean measurements of the granulomas did not vary significantly during the study period. It was possible to observe a more increased volume secondary to the inflammation against the HA at the beginning than at the end of the experimental period. Perhaps with an experimental period longer than 60 days HA granuloma might be significantly reduced.

Our results lead us to conclude that the non-absorbable microgranular semi-solid HA was well tolerated by the animals studied with maintenance of the infiltrated volume and may be useful for filling the anophthalmic cavities. However, it is necessary to carry out a study involving a longer time of observation of the granulomas formed and to develop more precise techniques of HA infiltration before this substance can be indicated for clinical use.

\section{References}

1. Leitha T (1995). Three-phase bone scintigraphy of hydroxyapatite ocular implants. European J ournal of Nuclear Medicine, 22: 308-314.

2. Hashimoto $M$, Rodrigues $A C$, MoraesSilva MRB \& Schellini SA (1994). Cavidade anoftálmica - causas, reconstrução e complicações. Revista Brasileira de Oftalmologia, 53: 517-522.
3. Taga EM (1991). Hidroxiapatita Microgranular Viscosa (uso em odontologia na Faculdade de Odontologia de Bauru, USP). Apostila do Departamento de Bioquímica, USP, Bauru, SP, Brazil.

4. Montgomery DC (1991). Design and Analysis of Experiments. 3rd edn. J ohn Wiley, New York, NY, USA.

5. Rosner M, Edward DP \& Tso MOM
(1992). Foreign-body giant-cell reaction to the hydroxyapatite orbital implant. Archives of Ophthalmology, 110: 173-174.

6. Goldberg RA, Dresner SC, Brasloso RA, Kossovisky N \& Legmann A (1994). Animal model of porous polyethylene orbital implants. Ophthalmic Plastic and Reconstructive Surgery, 10: 104-109. 